NBER WORKING PAPER SERIES

\title{
PRICING RATE CAPS ON DEFAULT-FREE
} ADJUSTABLE-RATE MORTGAGES

Stephen A. Buser

Patric H. Hendershott

Anthony B. Sanders

Working Paper No. 1525

NATIONAL BUREAU OF ECONOMIC RESEARCH 1050 Massachusetts Avenue Cambridge, MA 02138 December 1984

Hendershott was a Visiting Scholar at the Federal Home Loan Bank of San Francisco when this research commenced. The research reported here is part of the NBER's research program in Financial Markets and Monetary Economics. Any opinions expressed are those of the authors and not those of the National Bureau of Economic Research. 
A model is developed and utilized in this paper to value a life of loan interest rate cap on an ARM that reprices monthly. The value of the cap is seen to depend importantly on both the slope of the term structure and the variance of the one month rate. However, the cap value is not sensitive to the source of the slope of the term structure -- what precise combination of interest rate expectations and risk aversion determined the slope. This insensitivity is fortunate because of the great difficulty of knowing at any point in time why the term structure is what it is.

Given the variation in the slope of the term structure and the variance of the one month rate that occurred over the 1979-84 period, the addition to the coupon rate on a one-month ARM that lenders should have charged for a 5 percent life of loan cap has ranged from 5 to 40 basis points.

Stephen A. Buser

Hagerty Hall

Ohio State University

1775 College Road

Columbus, $\mathrm{OH} \quad 43210$

(614) 422-5719
Patric H. Hendershott Hagerty Hall Ohio State University 1775 College Road Columbus, $\mathrm{OH} \quad 43210$ (614) 422-0552
Anthony Sanders Hagerty Hall Ohio State University 1775 College Road Columbus, $\mathrm{OH} \quad 43210$ (614) 422-3217 
Pricing Rate Caps on Default-Free Adjustable-Rate Mortgages Stephen A. Buser, Patric H. Hendershott and Anthony B. Sanders

Adjustable rate mortgages (ARMs) have become an important component of housing finance. Over 60 percent of conventional mortgage loans closed during 1984 were ARMs, and this portion will probably exceed 65 percent in the last half of the year. The vast majority of ARMs have caps on how fast and/or how much overall the rates can rise. Survey data (Lea, 1984) indicate an enormous variation in charges for rate caps. Moreover, on average thrifts do not appear to be charging a greater coupon rate on capped ARMs than on noncapped ARMs. To our knowledge, only two studies have attempted to model formally the value of restrictions on contract rate adjustments. Cox, Ingersoll and Ross (CI\&R, 1980) provide a closed-form solution for the value of a uniform lifeof-loan cap on a perpetual instrument. To derive their equation, they assume that: (I) the coupon payment on the instrument freely fluctuates with the short-term rate of interest, subject to the cap restriction, and (2) the short-term interest rate follows a diffusion process with a constant elasticity of variance. Pozdena and Iben (P\&I, 1984) employ numerical procedures to value the life-of-loan cap on a 30-year instrument with a linear amortization schedule. Like CI\&R, P\&I assume that the coupon payment freely fluctuates with the short-term rate of interest subject to a uniform life-of-loan cap. However, P\&I assume that process governing the short-term rate is discrete (geometric binomial) rather than continuous. Both sets of authors assume a zero drift in interest rates.

Our model blends and extends these two studies. Like P\&I, we examine 30-year contracts, rather than the perpetual instrument studied by CI\&R, and we employ numerical procedures. However, we assume that the short-term rate 
follows a diffusion process, as in the CI\&R model, into which we introduce a mean-reverting drift. We compute the sensitivity of the value of life-of-loan interest rate caps to empirically relevant variations in the term structure of interest rates (owing, alternatively, to variations in the expected drift in rates and in risk aversion) and in the uncertainty of interest rates around the expected path.

Our paper contains two large sections and a short summary. In section I we describe a standard model for valuing any default-free interest-dependent claim and then tailor the generic model to an ARM with a life-of-loan rate cap. We begin section II with a discussion of plausible ranges of all the key parameters determining the value of rate caps and then present, describe, and interpret our simulation results, which are summarized in section III.

\section{Model Specification}

General Assumptions

The general setting of our model for pricing any default-free contract is described by four assumptions (see Vasicek (1977), Cox, Ingersoll and Ross (1978), Dunn and McConnell (1981) or Buser and Hendershott (1984)].

A.l The spot rate of interest $(r)$ follows a mean reverting process:

$$
d r=k(\mu-r) d t+\sigma(r) d z
$$


where $\mu$ is the steady-state mean, $k$ is the speed of adjustment, $\sigma(r)$ is the standard deviation of the spot rate, and $d z$ is a wiener process.

A.2 The value of a default-free contract is a function only of $t$ ime ( $t$ ) and the prevailing spot rate of interest:

$$
B=B(t, r)
$$

A.3 Interest dependent claims, such as B, generate expected rates of return that satisfy the zero-arbitrage risk/return relation (see Merton [1973]):

$$
\alpha(r, t)+c(r, t) / B=r+\lambda(r) \beta(r, t)
$$

where $\alpha($.$) and \beta($.$) are functions that measure the mean and standard$ deviation of the rate of change in the security's value; $c($.$) is the$ cash flow for the security; and $\lambda(r)$ is the market price of interest-rate risk.

A.4 The standard deviation of the spot rate and the market price of interest-rate risk vary with the square root of the spot rate:

$$
\sigma(r)=\sigma r^{\frac{1}{2}}
$$

$$
\text { and } \quad \lambda(r)=\lambda r^{\frac{1}{2}} \text {, }
$$


where $\sigma$ and $\lambda$ are constants, the latter being a transformed price of risk which we refer to as "the risk aversion parameter." The square root relation is computationally convenient, due to the work of Cox, Ingersoll and Ross (1978) which derives an explicit expression for $q \lambda$. (Moreover, Buser and Hendershott (1984) report that the $\frac{1}{2}$ coefficient is as consistent with return data as are coefficients of 0 and 1.$)$

By applying Ito's Lemma to equation (1), we represent the mean and variance of changes in interest-dependent claim values as:

$$
\begin{aligned}
& \alpha=\left[B_{t}+k(\mu-r) B_{r}+\frac{1}{2} \sigma{ }^{2} r B_{r r}\right] / B \text { and } \\
& \beta=\sigma r^{\frac{3}{2}}\left(-B_{r}\right) / B
\end{aligned}
$$

Combining (6) with (3) reproduces the standard pricing equation:

$$
B_{t}+[k(\mu-r)+\lambda \sigma r] B_{r}+\frac{1}{2} \sigma^{2} r B_{r r}+c(r, t)-r B=0 .
$$

In principle, it is possible to solve this equation for given specifications of : (1) the cash flow, $c(r, t) ;(2)$ a terminal value condition; and (3) boundary conditions for extreme values of the spot rate. Except as noted in the specification of the contract assumptions, we employ the standard boundary conditions [see Dunn and McConnell (1981)]: (1) any fixed-rate or capped-rate bond becomes worthless as the spot rate approaches infinity, and (2) the value of the bond at a zero spot rate is determined by the corresponding special case of (6) which serves as a "natural" boundary condition, i.e., variance in the spot rate, $\sigma^{2} r$, is zero at the origin so that the second-order difference equation is reduced to a first-order difference equation: 


$$
B_{t}+k \mu B_{r}+c(0, t)=0 \text {. }
$$

In the absence of a general analytic solution, we employ numerical procedures that are analogous to the "implicit-difference method" described by Brennan and Schwartz (1977).

\section{Contract Assumptions}

In addition to the aforementioned general assumptions, we impose two contractual assumptions that allow us to price adjustable-rate mortgages subject to rate caps. We state these assumptions in terms of discrete time intervals to reflect the numerical procedures that we use to value the contracts.

B.1 The life of adjustable rate mortgages $(T)$ is 360 months. Two amortization schedules are examined: nonamortization and linear amortization. The conventional fully-amortizing contract will always fall between these two extremes because amortization goes to zero as the coupon rate (i) goes to infinity and approaches linearity as the coupon approaches zero. Given the two principal repayment schedules, we can define the cash flows of the corresponding securities. For the nonamortizing contract, the cash flow is the product of the coupon rate and the par value prior to maturity and this plus par (PAR) at maturity. For the linearly amortizing contract, the cash flow consists of a principal payment and interest based on the declining mortgage balance. Thus, the cash flows in these two cases are given by: 
$c_{t}^{N}=i_{t-1}(P A R)$

$c_{t}^{L}=\frac{P A R}{T}+i_{t-1}(P A R) \frac{T-t+1}{T}$,

where $\mathrm{N}$ and $\mathrm{L}$ denote the nonamortization and linear amortization regimes and $t$ refers to the end of period $t$. With these cash flows, the terminal condition or value at maturity is zero in both cases.

B.2 The ARM coupon rate is adjusted each period (month) subject to an interest rate cap:

$$
i_{t}=\min \left(r_{t}+m, i_{0}+x\right)
$$

where $\mathrm{m}$ is the markup, and $\mathrm{x}$ is the amount that the current coupon may be above the initial contract rate. The markup is zero when no caps exist $(x=\infty)$ and will be higher the "tighter" is the life-ofloan cap being analyzed (smaller is $\mathrm{x}$ ). The model solves for the $\mathrm{m}$ which, with the $C$ specifications, forces $B$ in (7) to PAR.

\section{Simulation Results}

\section{$\underline{\text { Parameter Values }}$}

In an earlier estimation of equation (1), Buser and Hendershott (1984) found $\mathrm{k}$ to be in the 0.05 to 0.25 range and $\sigma$ to vary between 0.02 (in the January 1970 - October 1979 period) and 0.05 (between November 1979 and December 1983). We set $k=0.1$ in our base case, and we examine the sensitivity of our simulations to values as low as 0.01 (effectively no mean 
reversion) and as high as $0.2 .^{1}$ More recent data suggest that $\sigma$ has receded to 0.04. We take this as the base parameter and test the sensitivity of the estimates to values as low as 0.02 and high as 0.06 . We set the spot rate of interest, $r$, equal to 0.1 , roughly its value in 1984 .

To obtain realistic estimates of the values of the interest rate caps, the remaining parameter values must be specified carefully relative to the spot rate. More specifically, we need to specify base values of $\mu$ and $\lambda$ such that the implied spread between yields on long- and short-term Treasury securities approximates the average historical spread, and we need to identify respective ranges for $\boldsymbol{\mu}$ and/or $\boldsymbol{\lambda}$ that are consistent with observed changes in the spread between yields on long- and short-term Treasuries. To this end, the spreads between the yields on 30 year and 3 month Treasuries, as well as the value of the latter, over the past dozen years are listed in Table 1 . The overall average spread is nearly a full percentage point, and we interpret this average as representative of the "normal" term structure. The spread exceeded three percentage points in parts of 1975-77, 1980, and 1982-84; we refer to this range as a "steeply upward sloping" term structure. On the other hand, the annual average spread was minus one to minus one and a quarter percentage points in 1979 and 1981; this range is labelled a "steeply negatively sloped" term structure.

To establish a plausible bound for $\lambda$ consistent with the average one percentage point upward slope in the term structure over the 1973-84 period, we set $\mu-r=0$ and generate an implied value of $\lambda \sigma=0.0222$. Higher values of $\lambda$ imply a negative average value of $\mu-r$ during a period of generally rising interest rates (the three month rate rose from 5.20 percent in January 1973 to 10.07 percent in May 1984) which seems unlikely. We take risk neutrality $(\lambda=0)$ as our second limiting case and generate an implied $\mu-r=$ 0.0234 . 
Table 1: Yield Curve Data

Spread between 30-Year and 3 Month

Treasuries quoted on Bond-Equivalent Basis

Average

1973

1974

1975

1976

1977

1978

1979

1980

1981

1982

1983

1984

(through May)

Average

0.97

Source: Salomon and Hutzler.

Maximum Minimum

0.02

0.03

2.24

2.83

2.40

1.10

$-1.01$

3.34

2.09

3.95

2.99

2.74

2.61

\author{
Average \\ 3-Month Rate
}

6.97

7.95

5.97

5.11

5.28

7.32

10.21

11.75

14.67

11.09

8.83

1.90

9.59

2.49 
Table 2 indicates variations in interest-rate expectations and in the price of risk that would generate a spread between 30-year and 3 month Treasury rates ranging from roughly $-2 \frac{1}{2}$ percentage points to $3 \frac{1}{2}$ percentage points, given these bounds on plausible average values of $\mu-r$ and $\lambda$. The yield spread data in the first column were generated by varying $\mu-r$ over 2 percentage point increments (as indicated in the second column) and calculating the 30 year -3 month yield spread for a $\lambda \sigma$ of 0.0222 . The third column indicates the $\mu-r$ values that are consistent with the first column and $\lambda=0$. The fourth column contains the prices of risk that are consistent with the computed yield spreads shown in the first column assuming flat interest-rate expectations, and the fifth column gives the prices assuming $\mu-r=0.0234$. The table suggests that variations in either $\mu-r$ over a 12 or 13 percentage point range or in $\lambda \sigma$ over a 0.14 range would account for the swings in the yield curve observed over the $1973-84$ period. $^{2}$

The Value of a Five Percent Life of Loan Rate Cap

Our first task is to determine the importance of the slope of the yield curve to the value of life of loan rate caps. Table 3 contains estimates of the value of a five percent life of loan cap under different assumptions regarding both the observed slope of the yield curve and the sources of that slope $(\mu$ and $\lambda)$. All values are predicated on $k=r=0.1$ and $\sigma=0.04$, and the ranges of estimates in the table reflect the two amortization schedules, with zero amortization giving slightly larger values. Because the life of loan cap limits the coupon rate, zero amortization, which occurs as the coupon approaches infinity, understates the slowest feasible amortization; the linear amortization assumption, which can be interpreted as allowing for some early 


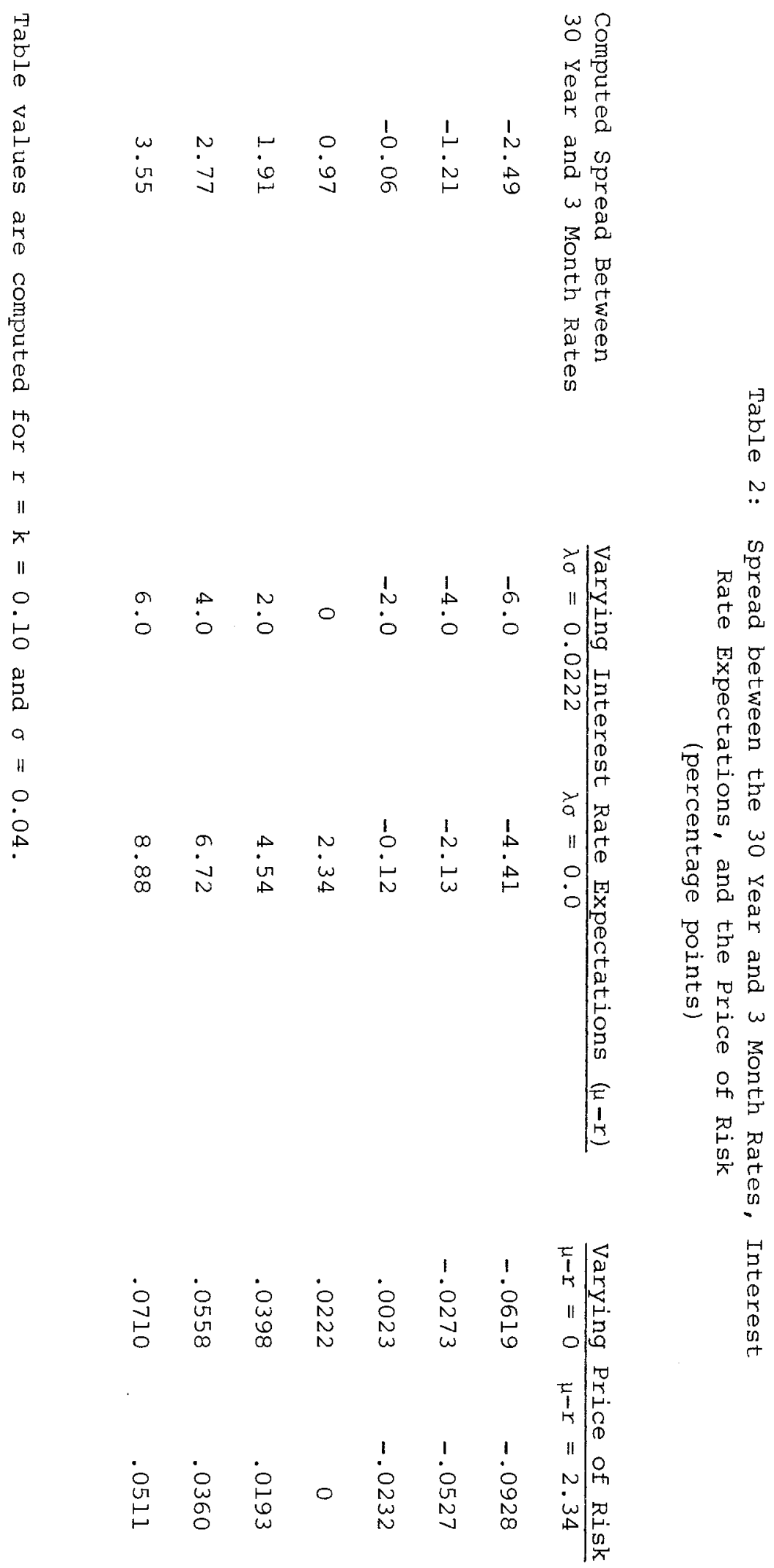


Table 3: Value (in Basis Points) of Five Percent Life of Loan Cap for Various values of the Observed Yield Curve Induced by Changes in Risk Aversion or in Interest Rate Expectations

\begin{tabular}{|c|c|c|c|c|}
\hline \multirow{2}{*}{$\begin{array}{l}\text { Spread Between } \\
30 \text { Year and } \\
3 \text { Month Rates }\end{array}$} & \multicolumn{2}{|c|}{$\begin{array}{l}\text { Varying Interest Rate } \\
\text { Expectations }(\mu-r)\end{array}$} & \multicolumn{2}{|c|}{ Varying Risk Aversion $(\lambda)$} \\
\hline & $\lambda \sigma=0.0222$ & $\lambda \sigma=0$ & $\mu=0.10$ & $\mu=12.34$ \\
\hline-2.49 & 0 & 0 & 0 & 0 \\
\hline-1.21 & 1 & 0 & 0 & 0 \\
\hline-0.06 & 3 & 2 & 2 & 1 \\
\hline 0.97 & $7-9$ & $5-7$ & $7-9$ & $5-7$ \\
\hline 1.91 & $15-21$ & $12-18$ & $17-25$ & $14-21$ \\
\hline 2.77 & $30-41$ & $26-36$ & $35-49$ & $32-45$ \\
\hline 3.55 & $50-70$ & $46-64$ & $56-79$ & $56-79$ \\
\hline
\end{tabular}

Table values computed for $k=r=0.1$ and $\sigma=0.04$. 
repayments, is clearly the more plausible and thus we discuss only the lower cap values. The cap value is obviously sensitive to the slope of the yield curve, being negligible at flat or negative slopes but nearly a half percentage point at very steep positive slopes. But the value is not sensitive to the source of the slope. For example, when the price of risk is varied from zero to 0.0222 , the cap value never varies by over 4 basis points over the wide range of interest rate expectations and resulting term structure assumptions (compare the second and third columns). Similarly, when the slope of the term structure is altered over the full $-2 \frac{1}{2}$ to $+3 \frac{1}{2}$ percentage point range, the cap value rises by only 6 basis points (10 percent) more if the alteration is caused by increased risk aversion rather a switch from steeply falling rate expectations to sharply rising expectations (compare the second and fourth columns).

our second task is to determine the sensitivity of the value of the five percent rate cap to the variance of interest rates. The cap values are shown in Table 4 for $\sigma^{\prime}$ s of $0.02,0.04$ and 0.06 . Because the slope of the term structure matters (but not its source), the cap value is computed at three different term structures. In these calculations, $k=r=0.1$; we maintain $\lambda \sigma$ at 0.0222 and obtain the required term structures by varying $\mu$. The middle (median variance) row reproduces some of the data from Table 3. The low variance rate (top row) eliminates the cap value at the normal term structure and sharply reduces the value at a $23 / 4$ percent positively sloped yield curve. In contrast, the high variance rate creates a 7 basis point value even with the negatively sloped yield curve, a 25 basis point value with the normal yield curve, and a 55 to 70 basis point value for a steeply upward sloping yield curve. To summarize, the value of the cap is worth less than 10 basis points 
Table 4: Effect of Interest Rate Variance on the Value of a Five Percent Life of Loan Cap for Different Term structures

(basis points)

\begin{tabular}{c|ccc} 
Variance \\
$\begin{array}{c}\text { of Interest Rates } \\
\text { Structure }\end{array}$ & $\begin{array}{c}\text { Steeply } \\
\text { Falling } \\
(-121)\end{array}$ & $\begin{array}{c}\text { Normal } \\
(97)\end{array}$ & $\begin{array}{c}\text { Steeply } \\
\text { Rising } \\
(277)\end{array}$ \\
\hline low (0.02) & 0 & 0 & $11-18$ \\
medium (0.04) & 1 & $7-9$ & $30-41$ \\
high (0.06) & $7-8$ & $24-28$ & $55-70$
\end{tabular}


when the yield curve is negatively sloped or when it is normally sloped and the variance is not extraordinarily large. For a significantly upward sloped yield curve and moderate variance or normal yield curve and high variance, the cap is worth a quarter percentage point. With both a steeply sloped yield curve and high variance, the cap is worth a half to three-quarters percentage point.

\section{The Value of Life of Loan Rate Caps from Zero to Ten Percent}

The value of life of loan rate caps from zero to ten percent are plotted in Figure 1 for $\sigma=0.04, \lambda \sigma=0.0222, r=0.1$ and $\mu$ ranging from 0.06 to 0.14 . The bands reflect the two limiting amortization assumptions. With constant rate expectations, a zero cap is worth approximately 125 basis points. With expectations of rising interest rates $(30$ year rate -3 month rate $=23 / 4$ percentage points), the difference is a full 250 basis points; with expectations of falling rates, the difference is only about 40 basis points. One is tempted to view an ARM with a zero rate cap as a standard 30-year fixed-rate mortgage (FRM) and thus to interpret the value of the cap as the excess of the required coupon on a par-value FRM over the prevailing spot rate. However, the value of the zero cap may be either an over or understatement of this excess. The value is an overstatement because household borrowing rates on FRMs do not instantaneously decline in response to decreases in market interest rates, as is the case with short-term ARMs. On the other hand, the value understates the excess because a refinanced FRM has a zero cap from that point while a downward repriced ARM has a cap equal to the difference between the original rate and the new lower rate. The value of long-term commitments with rate caps falls sharply as the cap is loosened. A 5 percentage point cap 


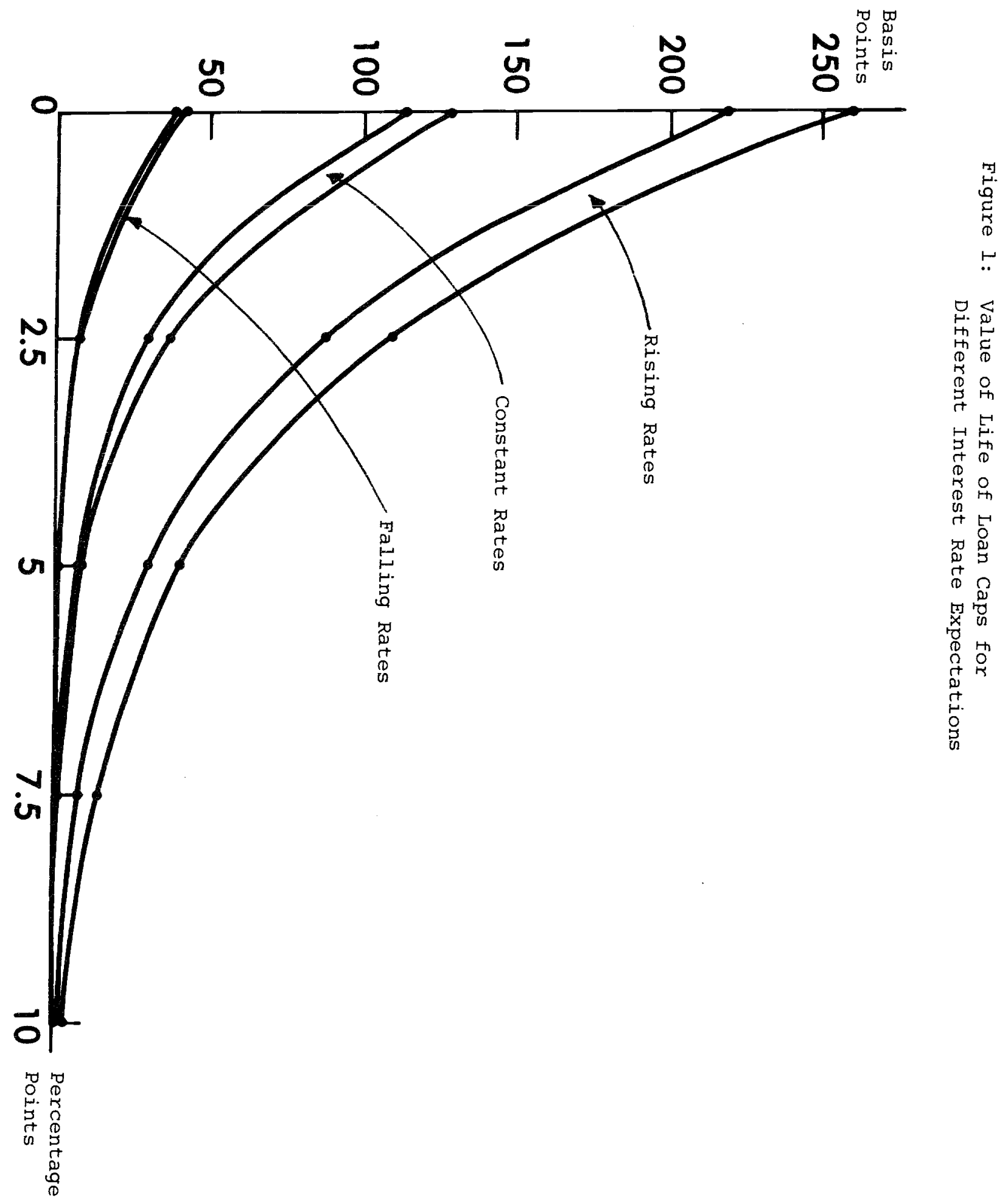


is worth less than 10 basis points unless rates are expected to rise, and a 10 point cap is worth less than 5 basis points even when rates are expected to increase sharply.

The value of the life of loan rate caps based upon different values of the interest rate variance are plotted in Figure 2 lother assumed parameter values are $r=\mu=0.1$ and $\lambda \sigma=0.0222$ ). The points on the vertical axis again represent a rough approximation to the difference between the required coupon on a par-value FRM and the spot rate. These differences corraborate the relative insensitivity of fixed-rate mortgage coupons to the variance noted by Buser and Hendershott (1984); the difference varies only between 110 and 140 basis points for values of $\sigma$ ranging all the way from 0.02 to 0.06 . The relative sensitivity is much larger for interest rate caps on our one-month ARM. With a cap of $2 \frac{1}{2}$ percentage points the range is 12 to 55 basis points; with a 5 point cap the range is 1 to 20 basis points.

Our valuations of the life of loan cap are far lower than those computed by Pozdena and Iben (1984). They find a zero cap to be worth about five percentage points, roughly four times our $1 \frac{1}{4}$ percentage point value with a normal term structure and twice our highest value obtained with a steeply upward sloping term structure. They value the 5 point life of loan cap at two to three percentage points, many times greater than our high-variance, steeply-upward-sloping term-structure value of 60 basis points.

One possible source of the difference in our cap values from those of Pozdena and Iben is our use of a mean reversion interest rate process which clearly lowers cap values. However, calculations with $k$ equal to 0.0 (other parameters are $r=\mu=0.1, \sigma=0.04$ and $\lambda \sigma=0.0222$ ) result in the zero cap value rising by only about a third, not the multiple of three or four necessary 


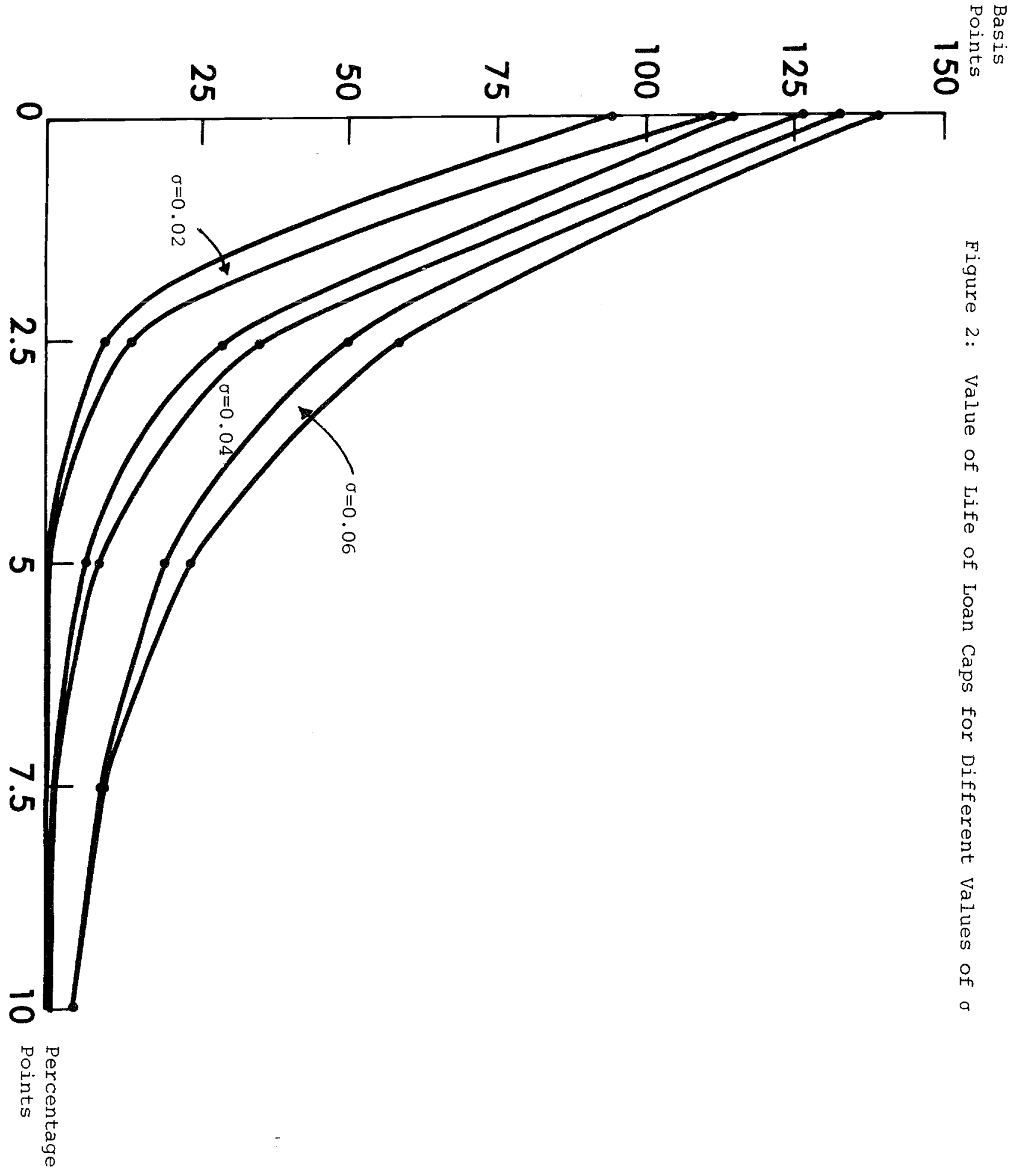


to explain differences in our calculations. Similarly, the estimated value of the 5 percent life of loan cap is still only 30 to 40 basis points, far below the 2 to 3 percentage points reported by Pozdena and Iben.

\section{Summary}

Our model extensions were enumerated in the introduction and are thus not listed here. Rather, we simply summarize our most interesting simulation results. For brevity, we will couch them in terms of the calculated value of the fair mark-up in the coupon rate on our one-month ARM for a five percent life of loan rate cap.

The value of the cap is sensitive to the slope of the yield curve. With a mildly negatively sloped term stxucture, the cap has no value; with a normal structure, the value is 5 to 10 basis points; and with a sharply rising structure ( $3 / 4$ percentage points) the value is 30 to 40 basis points. However, the cap value is insensitive to the source of the slope of the term structure -- what precise combination of interest rate expectations and risk aversion determined the slope. This insensitivity is fortunate because of the great difficulty of knowing at any point in time why the term structure is what it is.

The level of the variance of rates matters. With a steeply rising term structure, the value of the five percent cap falls from 30 to 15 basis points as the variance declines from 0.04 to 0.02 and rises to 55 basis points as the variance rises to 0.06 . With a normally sloped yield curve, the impact of varying the variance is less absolutely but more proportionately. The 8 basis point value goes to zero at the low variance and up to 25 basis points with the high variance. For all values of the term structure and variance, our 
computed values of the five percent life of loan cap are a small fraction of those reported by Pozdena and Iben (1984). This difference is not due to our use of a mean reversion process. 
NOTES

1. With this assumption, half of an initial gap between $\mu$ and $r$ would be expected to disappear in seven years.

2. With a larger $k$, smaller variations in $\mu-r$ are sufficient. To illustrate, with $k=0.2$, a swing of 9 percentage points is ample. 
REFERENCES

[1] S. A. Buser and P.H. Hendershott, Pricing Default-Free Fixed-Rate Mortgages, Housing Finance Review, 3, 1984.

[2] M. J. Brennan, and E. S. Schwartz, Savings Bonds, Retractable Bonds, and Callable Bonds, Journal of Financial Economics 5, 67-88, 1977.

[3] J. C. Cox, J. E. Ingersoll and S. A. Ross, A Theory of the Term Structure of Interest Rates, Research Paper No. 468, Graduate School of Business, Stanford University, 1978.

[4] - An Analysis of Variable Rate Loan Contracts, Journal of Finance, 35, no. 2, 389-403, 1980.

[5] K. B. Dunn and J. J. McConnell, Valuation of GNMA Mortgage-Backed Securities, Journal of Finance 36, no. 3, 599-616, 1981.

[6] R. C. Merton, Theory of Rational Option Pricing, Bell Journal of Economics and Management Science 4, 141-232, 1973.

[7] R. J. Pozdena, and Ben Iben, Pricing Mortgages: An Options Approach, Economic Review, Federal Reserve Bank of San Francisco, 1984.

[8] O. Vasicek, An Equilibrium Characterization of the Term Structure, Journal of Financial Economics 5, 177-188, 1977. 